www.jmscr.igmpublication.org Impact Factor 5.244

Index Copernicus Value: 83.27

ISSN (e)-2347-176x ISSN (p) 2455-0450

crossref DOI: _https://dx.doi.org/10.18535/jmscr/v4i12.08

\title{
Journal Of Medical Science And Clinical Research
}

\section{Original Research Article \\ A Clinicopathological Study and Management of Diabetes Skin Ulcers - An Institutional Experience}

\author{
Authors \\ Padmanabh S Inamdar, Prateik Mote, Jayaprakash Kashalikar, Madhukar Mote \\ Department of Surgery, Bharati Vidyapeeth Medical College and Hospital, Sangli, Maharashtra, India \\ Corresponding Author \\ Dr Padmanabh S Inamdar \\ Email: docpadmanabh@gmail.com, Contact No.: 9421420540
}

\begin{abstract}
Background: Diabetes is a worldwide problem. A good number of diabetic patients develop wound in one point of time or other during the course of their illness. The etiopathogenesis of diabetic lesions are multifactorial. Ulcer can develop anywhere on the body parts but foot is the most vulnerable part.

Aims and Objectives: Limb problems such as ulceration, infection, gangrene are quiet common in diabetic patients. So the study was taken up to identify the complications and to study the patients of Diabetes Mellitus having various skin lesions. We wanted to asses various methods of treatment adopted in these patients including length of stay, duration of required, types of treatment, Size of ulcer \& Ratio of ulcer over upper \& lower extremities, Morbidity \& Mortality.

Material and Methods: An observational study of 100 Patients clinically presenting with diabetic wound admitted \& treated in Department of Surgery, Bharati Vidyapeeth Deemed University Medical College \& Hospital, Sangli. Various factors affecting diabetic foot ulcers and its management were studied.

Results: Diabetes affects all age groups and mainly manifested in middle age. All the patients with diabetic wound had longer hospital stay as compared to non diabetic patients. Commonest presenting lesion in foot was ulcer followed by cellulites and gangrene. Most common causative organism was pseudomonas followed by staphylococcus aureus and $E$ coli. The etiopathogenesis of diabetic lesions are multifactorial. Diabetic neuropathies, vasculopathy, poor control of diabetes and bacterial infection are among the most common.

Key Words: diabetes mellitus, skin ulcers, wound dressing, skin grafting.
\end{abstract}

\section{INTRODUCTION}

Overall incidence of diabetics in India is $1.2 \%$. The death in each year is due to its complications ( $2.1 \%$ in urban, $1.5 \%$ in rural), which are usually common in age group of 40 - 60 years affecting both sexes equally ${ }^{01}$. The complications are more prevalent among the people of lower economic status due to negligence, illiteracy and poverty. Over the past few decades there has been an alarming rise in the prevalence of Diabetes. The WHO report says diabetes in India will rise from 135 million in 1995 to 300 million by 2025 and India will be diabetic capital of World ${ }^{02}$. The CPR (Crude prevalence rate) in the urban areas of India 
is thought to be 9 per cent. This means that India actually has the highest number of diabetic patients in the entire world. IGT (Impaired Glucose Tolerance) is also a mounting problem in India. The prevalence of IGT is thought to be around 8.7 per cent in urban areas and 7.9 per cent in rural areas. It is thought that around 35 per cent of IGT sufferers go on to develop type 2 diabetes, so India is genuinely facing a healthcare crisis. In India, the type of diabetes differs considerably from that in the Western world.

Limb problems such as ulceration, infection, gangrene are quiet common in diabetic patients. This account for frequent and prolonged hospitalizations, significant morbidity and even mortality and a rough estimates yield that $25 \%$ of all admissions of diabetics are due to wound problems and nearly 5-10\% needs amputation. Over the all non traumatic amputations $50 \%$ are related to diabetes. However with proper wound care this could be prevented or minimized. So the study has been taken up in our institute to identify the type of skin lesions in these patients and methods that can be used to treat these patients.

\section{MATERIALS AND METHODS}

The study was conducted in Department of Surgery, Bharati Vidyapeeth Deemed University Medical College \& Hospital, Sangli, which was sanctioned by Institutional Ethical Committee (BVDUMC\&H/Sangli/IEC/2013-14/ 48). An observational study was conducted on the patients admitted with diabetic wound in the Department of Surgery, Bharati Vidyapeeth Deemed University Medical College \& Hospital, Sangli from November 2013 to October 2015. Nearly 100 diabetic patients clinically presenting with wound were admitted \& treated in Department of Surgery, Bharati Vidyapeeth Deemed University Medical College \& Hospital, Sangli. Patients meeting the requirements of inclusion and exclusion criteria were enrolled in this study after taking an informed written consent. Inclusion criteria included all the patients treated with various skin ulcers having diabetes irrespective of age and sex. Exclusion Criteria included non diabetic skin ulcers secondary to arterial diseases, tuberculosis, malignant ulcers and venous ulcers. Detailed history was taken followed by examination and findings were tabulated. Relevant blood urine and radiological investigations were conducted on patients and treatment modality used to heal the ulcer was carefully noted. Management of wound was done with antibiotics, local application of antiseptics, vacuum assisted dressings, debridement of ulcers, skin grafting, amputation. All the data was entered in Microsoft Excel sheet and statistical analysis was done with the help of statistical software.

\section{RESULTS}

Out of 100 patients $69 \%$ cases were having uncontrolled diabetes and $31 \%$ cases having controlled diabetes with regular intake of oral hypoglycemic drugs or insulin. Youngest patient patient in our study was 36 years and oldest was 82 years with higher number of cases found in 60 79 years of age $(49 \%)$ followed by $40-59$ years of age $(43 \%)$ as shown in Fig 1. According to our study patients having uncontrolled diabetes are more prone to develop wound. In the present study, out 100 cases $30 \%$ cases is had cellulites at presentation, post operative wound seen in $32 \%$ (after I\&D, fasciotomy and debridement), spontaneous blister formation $15 \%$ cases \& abscess formation $15 \%$ as shown in Fig 2 . Ischemia was predominant cause for ulcer formation $(83 \%)$ and rest $(17 \%)$ cases were due to neuropathy (Fig 3). In $83 \%$ of cases ulcers were found in lower limb, remaining lesions were found on other parts of body. Our patients were managed by local dressing (local antiseptics) in 81 (39\%), mechanical debridement 59 (29\%), amputation $14(7 \%)$, skin grafting $14(7 \%)$ and sec. suturing $38(18 \%)$ patients as shown in (Fig 4). To control blood sugar levels $55 \%$ cases were managed by oral hypoglycemic drugs, $31 \%$ with insulin and rest (14\%) with dietary modification alone (Fig 5). Majority of the septic lesions yielded Pseudomonas organism on culture of pus 
(18\%) followed by Staphylococcus aureus, Escherichia coli, Proteus and streptoccocus (Fig 6). Most of them were sensitive to Ampicillin, Ceftriaxone, Gentamycin, Imipenem. Meropenem and Amikacin.

Duration of diabetes varied from 1 year to 22 years and many patients were diagnosed after the admission. Minimum stay in hospital was 6 days and maximum 66 days. Commonest presenting lesion was cellulitis $30 \%$, followed by gangrene, post-op and abcess. In this series 81 cases of diabetic foot were managed by daily dressing (e.g.
Betadine, Hydrogen peroxide, Eusol, Glycerine Magnesium Sulphate, Normal Saline, Amorphous Hydrogels and use of VAC in 2 cases) followed by, wound debridement, and slough excision. 65 postoperative cases considered in this study with diabetes, had purulent discharge for which daily dressing was done but most of the cases landed up in wound dehiscence. Secondary suturing was done in 38 cases to achieve healing. Split skin grafts, disarticulation, below knee amputation and above knee amputations were the other modes of treatment given.

Fig 1: Age and sex distribution of patients ( $77 \%$ case were male and $23 \%$ cases were female)

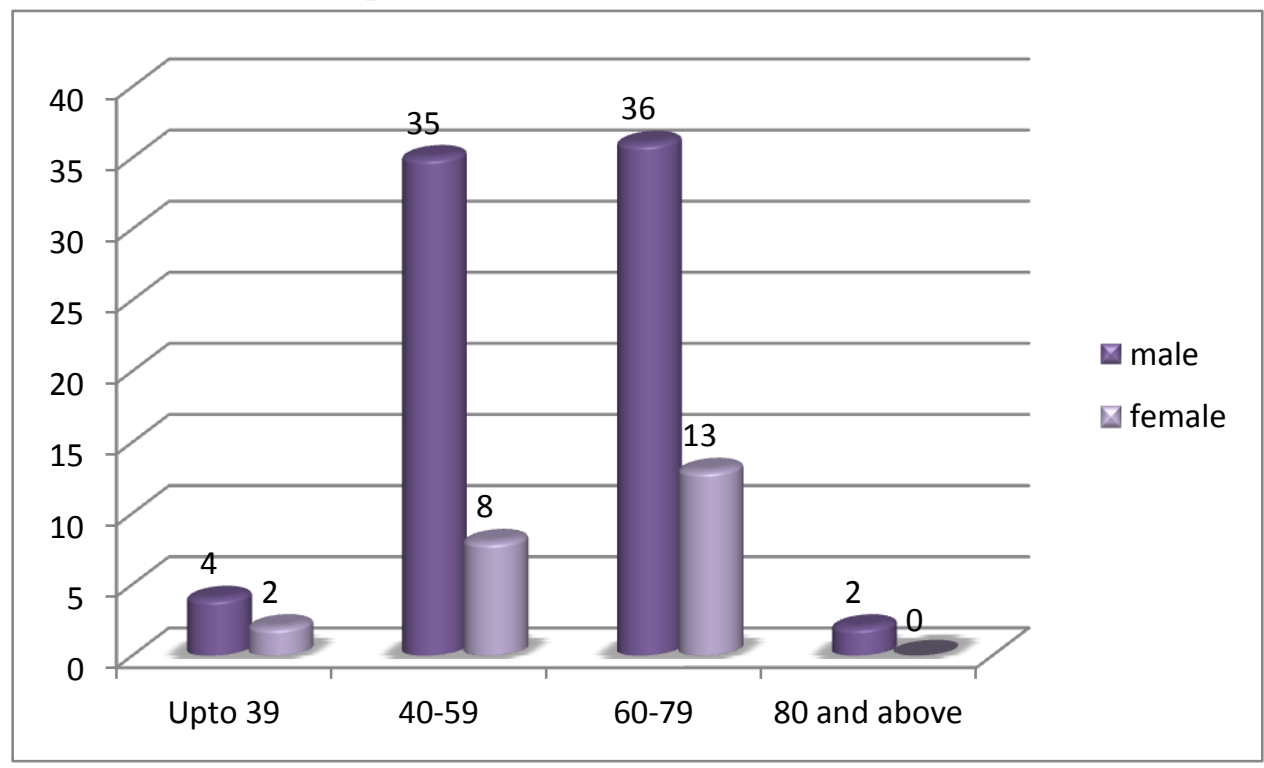

Fig 2: Type of skin lesions

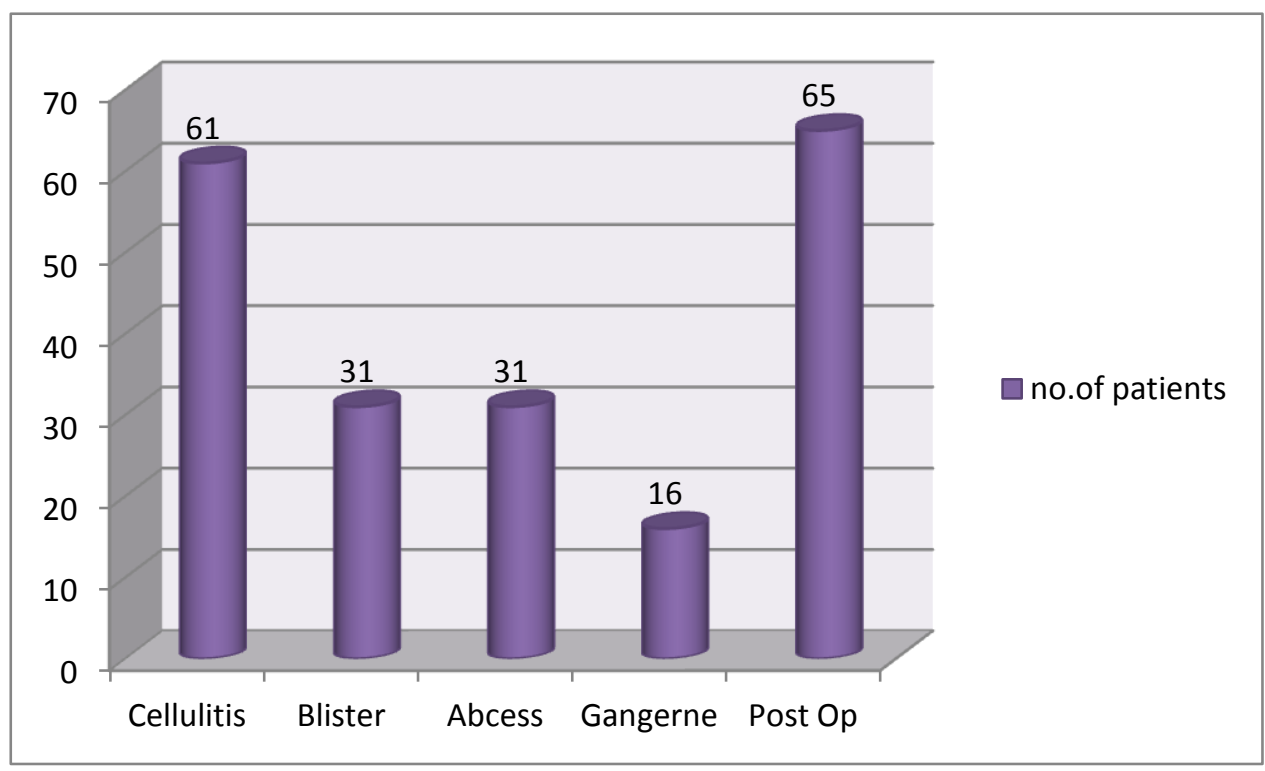


Fig 3: Causative factors for diabetic ulcer

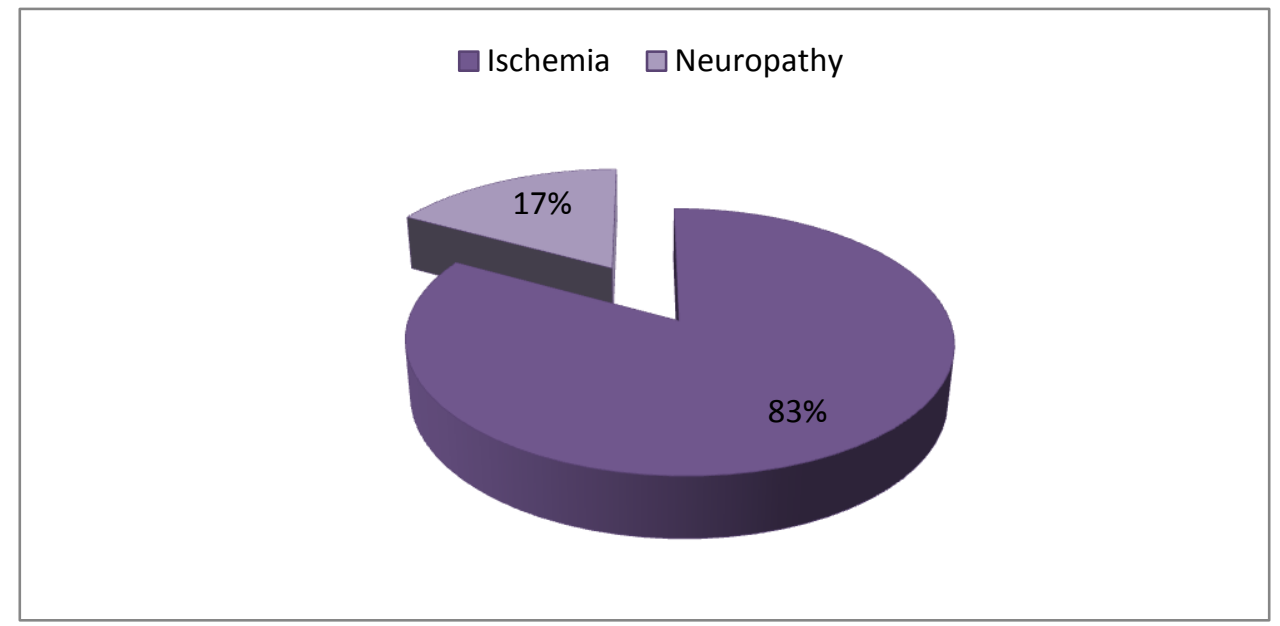

Fig 4: Type of Treatment received

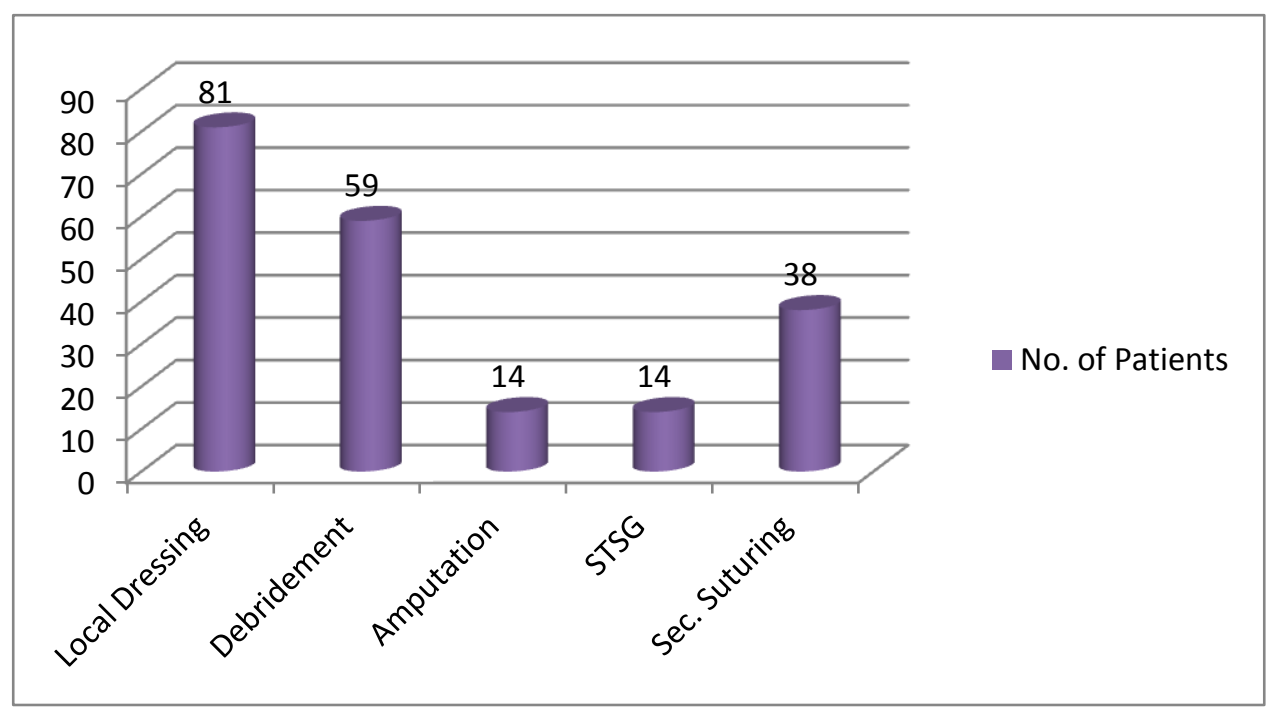

Fig 5: Type of Medication

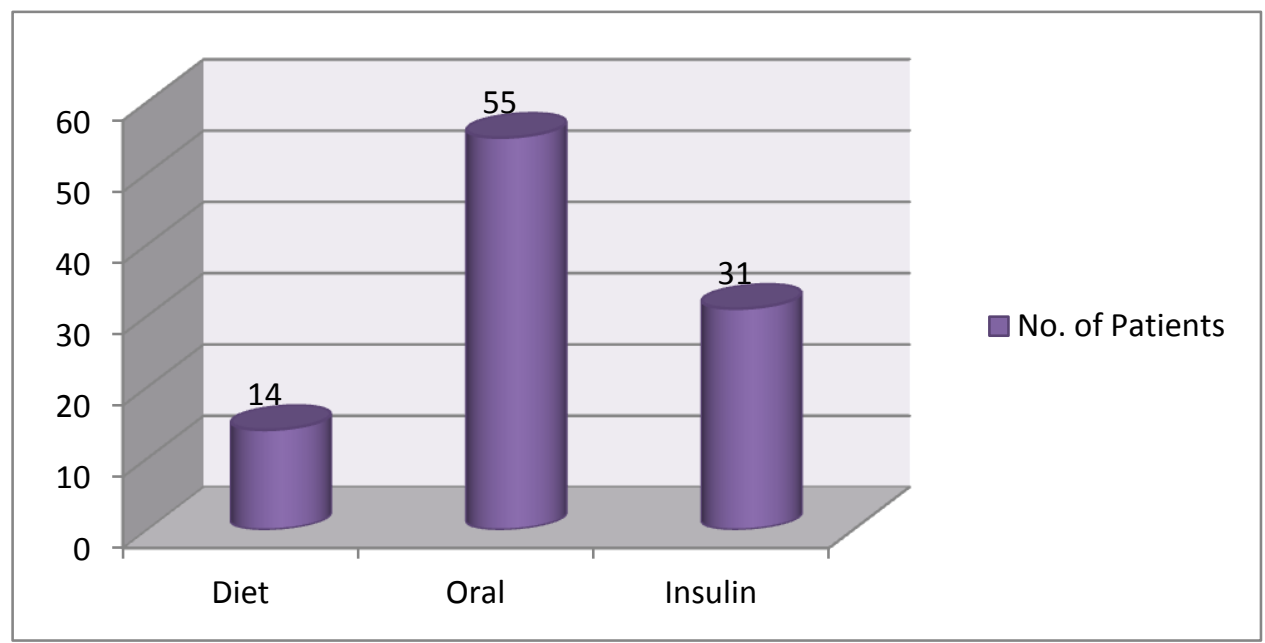


Fig 6: Culture and Sensitivity diabetic wounds

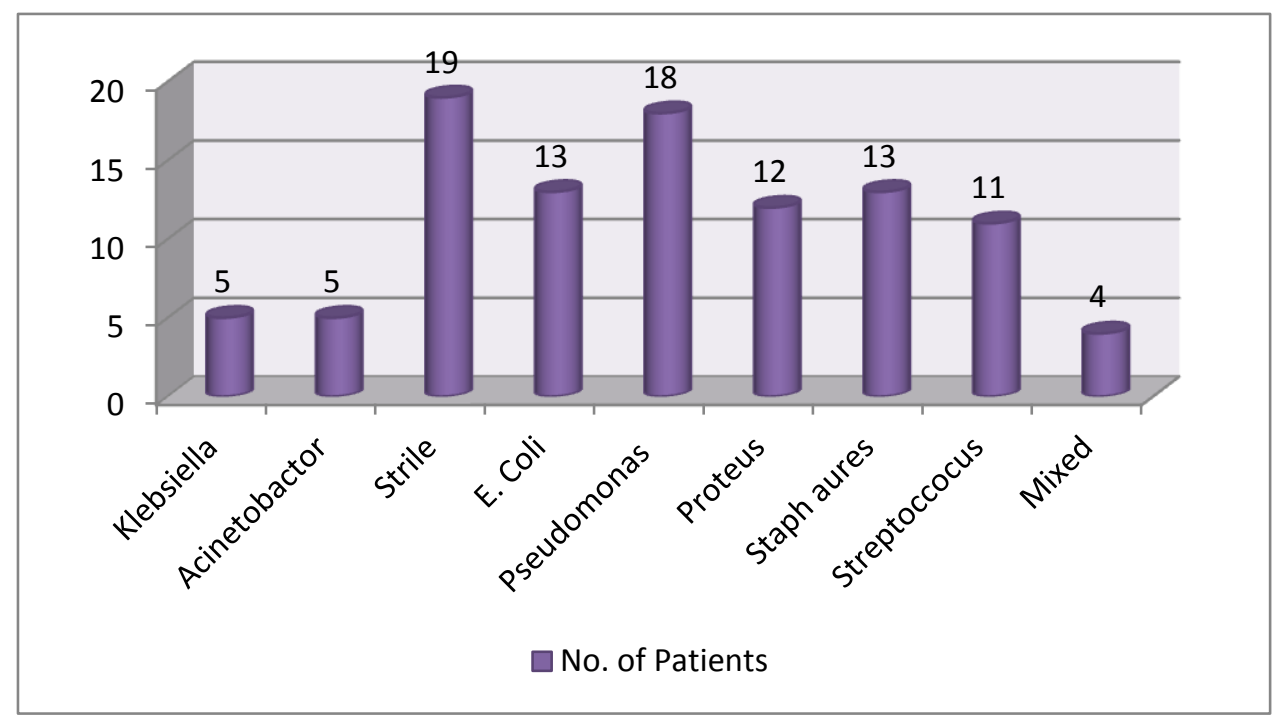

Table 1: Clinicopathological factors of study population $(\mathrm{N}=100)$

\begin{tabular}{|c|c|c|c|c|}
\hline \multirow{2}{*}{1} & \multirow{2}{*}{$\begin{array}{c}\text { Diabetic Status } \\
\text { Uncontrolled diabetes }\end{array}$} & \multicolumn{2}{|c|}{ No. of Patients } & \\
\hline & & 69 & & \\
\hline & Controlled diabetes & 31 & & \\
\hline 2 & Age groups in years & Male & Female & Total \\
\hline & Upto 39 & 4 & 2 & 6 \\
\hline & $40-59$ & 35 & 8 & 43 \\
\hline & $60-79$ & 36 & 13 & 49 \\
\hline & 80 and above & 2 & 0 & 2 \\
\hline 3 & Type of skin lesion & no. of patients & percentage & \\
\hline & Cellulitis & 61 & 30 & \\
\hline & Blister & 31 & 15 & \\
\hline & Abcess & 31 & 15 & \\
\hline & Gangerne & 16 & 8 & \\
\hline & Post Op & 65 & 32 & \\
\hline 4 & Causative factors fo & iabetic ulcer & & \\
\hline & Ischemia & 83 & & \\
\hline & Neuropathy & 17 & & \\
\hline 5 & Body Parts & No. of Cases & & \\
\hline & Trunk & 12 & & \\
\hline & Upper Limb & 5 & & \\
\hline & Lower Limb & 83 & & \\
\hline 6 & Type of Treatment & No. of Patients & Percentage & \\
\hline & Local Dressing & 81 & 39 & \\
\hline & Debridement & 59 & 29 & \\
\hline & Amputation & 14 & 7 & \\
\hline & STSG & 14 & 7 & \\
\hline & Sec. Suturing & 38 & 18 & \\
\hline 7 & Type of Medication & No. of Patients & Percentage & \\
\hline & Diet & 14 & 14 & \\
\hline
\end{tabular}




\begin{tabular}{|l|c|c|c|l|}
\hline & Oral & 55 & 55 & \\
\hline & Insulin & 31 & 31 & \\
\hline 8 & Oraganism Cultured & No. of Patients & Percentage & \\
\hline & Klebsiella & 5 & 5 & \\
\hline & Acinetobactor & 5 & 5 & \\
\hline & Strile & 19 & 19 & \\
\hline & E. Coli & 13 & 13 & \\
\hline & Pseudomonas & 18 & 18 & \\
\hline & Proteus & 12 & 12 & \\
\hline & Staph aures & 13 & 13 & \\
\hline & Streptoccocus & 11 & 11 & \\
\hline & Mixed & 4 & 4 & \\
\hline & & & & \\
\hline
\end{tabular}

\section{DISCUSSION}

The prevalence of diabetes India is projected to be $4.4 \%$ in the year 2015. The CPR (Crude prevalence rate) in the urban areas of India is thought to be 9 percent and in rural areas, the prevalence is approximately 3 per cent of the total population $^{03}$. Postoperative hyperglycemia - with or without reaching the threshold for diabetes is an independent predictor of surgical site infections. Epidemiologic studies suggest that $2.5 \%$ of diabetic patients develop diabetic foot (DF) ulcers each year and 15\% develop DF ulcers during their lifetime ${ }^{04}$. Patients with postoperative glucose levels of 111 to $140 \mathrm{mg} / \mathrm{dL}$ were 3.61 times more likely to develop an infection, and the odds were 12.31 times greater for those with glucose levels higher than $220 \mathrm{mg} / \mathrm{dL}^{05}$.

If post operative hyperglycemia is confirmed in future prospective studies to be an independent risk factor for post-surgical infection it would give surgeons a modifiable variable to reduce the incidence of postoperative infection. It has been well established that patients with diabetes have an increased risk of post-surgical and other nosocomial infections. The reason is unclear, but hyperglycemia has been suggested as a causative factor.

A surgical site infection is defined as an infection that develops within 30 days after an operation or within one year if an implant was placed, and the infection appears to be related to the surgery. Diabetes is a risk factor for nosocomial surgical site infections in patients. These patients are monitored closely in order to enhance surgical site infection control measures. The development of ulcer is traditionally considered to result from a combination of peripheral vascular disease, peripheral neuropathy and infection.

Among 100 cases of wound with diabetes that we studied prospectively, majority were in fourth decade of life similar to studies published by Wheel Lock and Root et al ${ }^{06}$, Donavan et al ${ }^{07}$. When sex distribution was compared males were more prone to develop skin ulcers probably as these are the people of the family who mostly working out door, and are more vulnerable for trauma and smoking. Similar distribution is seen in studies conducted by A. H. Khan et al ${ }^{08}$, Ali SM et al ${ }^{09}$, Gayle et $\mathrm{al}^{10}$. When cause for gangrene was investigated ischemic complications was the main reason in majority of our patients similar to study published by McNeely $\mathrm{MJ}^{11}$, Reiber GE ${ }^{12}$. In our study, among 28 cases who had gangrene, 24 cases are because of ischaemia, whereas in the remaining ${ }^{4}$, the cause was sepsis.

Diabetes also has a major role to play in delayed wound healing and the development of gangrene. ${ }^{13}$ Diabetics have a high risk of atherosclerotic peripheral vascular disease ${ }^{14,15}$. In combination with peripheral neuropathy and minor trauma it would be a cause of foot ulceration ${ }^{14}$. The presence of peripheral arterial disease has been cited by many authors as a risk factor for amputations in diabetics. ${ }^{16,17}$ It is 
irrefutable that the presence of peripheral vascular disease causes problems in the blood flow; adequate blood flow is essential for healing and for combating the severe infections that attack diabetic foot. Ramsay et $\mathrm{al}^{18}$ reported that majority amputations in their series were associated with peripheral vascular disease.

The amputation rate in present study is much lower $(7 \%)$ as compared to Collen's series ${ }^{19}$ $(38.6 \%)$ and Osaka kosainekin Hospital study ${ }^{20}$ $(52 \%)$. This could be due to availability of better modern modalities by which deterioration of lesion due to vascular and neuropathy could be further avoided. Future knowledge in this regard of different ways and efficacy of appropriate dressing material, combination of antibiotics covering bacteriostatic and bacteriocidal effects, would be helpful in early wound healing without any morbidity and mortality. Although gram positive cocci are the commonest organism isolated pseudomonas was the commonest organism in the present study followed by staphylococcus and streptococcus. In the present study, all patients required some surgical intervention at some point along with medical treatment.

Conservative treatment consisted of control of diabetes with Plain/Lente insulin, long acting insulin (insulin glargine) along with appropriate oral / intravenous antibiotics. Patients were also presented with neuropathy and they were treated with methyl Cobalamine and with pregabaline.

Diabetic ulcers were managed by daily dressing (e.g. Betadine, Hydrogen peroxide, Eusol, Glycerine Magnesium Sulphate, Normal Saline, Amorphous Hydrogels and VAC) followed by, wound debridement, slough excision disarticulation. All the patients with diabetic wound had longer hospital stay as compared to non diabetic patients. The long duration of hospitalization can be explained by the refractory to treatment of the lesions owing to lowered immunity of the body, hyperglycemia, impaired hormonal defense mechanisms and multidrug resistance of the organisms to antibiotic therapy.

\section{CONCLUSION}

Diabetes is a worldwide problem. A good number of diabetic patients develop wound at one point of time or other during the course of their illness. A significant number of such patients required longterm hospitalization and surgical intervention. Diabetes affects all age groups with male predominance. The etiopathogenesis of diabetic lesions are multifactorial and infecting organism are polymicrobial. Strict blood sugar control, daily dressing with proper antibiotic coverage and proper surgical management heals most of the wounds.

\section{REFERENCES}

1. Park's Text Book of Preventive and Social Medicine. 20th edition. Jabalpur, India: M/S Banarsidas Bhanot 2009; 340-342.

2. Sorganvi v, devarmani ss, angadi $\mathrm{mm}$, udgiri r. knowledge and its complications of diabetes amongst the known diabetic patients - a hospital based study. ijcrr. (2013), 5(22): 100-104.

3. V. Mohan, S. Sandeep, R. Deepa, B. Shah* \& C. Varghese. Epidemiology of type 2 diabetes: Indian scenario. Indian J Med Res 125, March 2007, pp 217-230.

4. Abolfazl Shojaiefard, Zhamak Khorgami, and Bagher Larijani; Independent risk factors for amputation in diabetic foot Int $\mathbf{J}$ Diabetes Dev Ctries. 2008 Apr-Jun; 28(2): 32-37.

5. Ashar Ata, Julia Lee, BS; Sharon L; Postoperative Hyperglycemia and Surgical Site Infection in General Surgery Patients. Arch Surg. 2010;145(9):858-864.

6. Wheollock FC Jr, Gibbons GW, Campbell D. Study of foot lesions in diabetes. Ann Surg. 1969;99:776.

7. John C Donavan, John L Rowbotham. Foot lesions in diabetes mellitus. Joslin's diabetes mellitus. Chapter 35. 13th edition. Philadelphia: Lea and Febiger; 732.

8. Zargar AH, Khan AK, Masoodi SR, Laway BA, Wani AI, Bashir MI, Dar FA. 
Prevalence of type 2 diabetes mellitus and impaired glucose tolerance in the Kashmir Valley of the Indian subcontinent. Diabetes Res Clin Pract. 2000 Feb; 47(2):135-46.

9. Ali L, Hussain MZ, Rumi MA, Banu A, Azad Khan AK; Effect of socioeconomic risk factors on the difference in prevalence of diabetes between rural and urban populations in Bangladesh. Diabetes Care. 1997 Apr; 20(4):551-5.

10. Gayle R, Benjamin AL, Gary NG. The burden of diabetic foot ulcers. The American Journal of Surgery 1998Aug 24; 176(Suppl 2A):65-105.

11. McNeely MJ, Boyko EJ, Ahroni Jh, et al. The independent contributions of diabetic neuropathy and vasculopathy in foot ulceration. Diabetes Care 995;18:216- 219.

12. Reiber GE, Vileikyte L, Boyko EJ, et al. Causal pathways for incident lowerextremity ulcers in patients with diabetes from two setting. Diabetes Ca r e 1999; 22:157-162.

13. Boulton AJ. The pathogenesis of diabetic foot problems: An overview. Diabetes Med. 1996;13:12-6.

14. Muller IS, de Grauw WJ, van Gerwen WH, Bartelink ML, van Den Hoogen HJ, Rutten GE. Foot ulceration and lower limb amputation in type 2 diabetic patients in Dutch primary health care.Diabetes Care. 2002;25:570-74.

15. Markowitz JS, Gutterman EM, Magee G, Margolis DJ. Risk of amputation in patients with diabetic foot ulcers: A claims-based study. Wound Repair Regen. 2006;14:11-7.

16. Miyajima S, Shirai A, Yamamoto SH, Okada N, Matsushita T. Risk factors for major limb amputations in diabetic foot gangrene patients. Diabetes Res Clin Pract. 2006; 71:272 -79.
17. Calle-Pascual AL, Garcia-Torre N, Moraga I, Diaz JA, Duran A, Moñux G, et al. Epidemiology of nontraumatic lowerextremity amputation in area 7, Madrid, between 1989 and 1999: a populationbased study. Diabetes Care. 2001;24:168689.

18. Scott S. Ramsay et al ;Incidence, outcomes, and cost of foot. Ulcers in patients with diabetes. JAMC 15(3):3942 January 2003.

19. Collens WS, Vlahos E, Dobkin Gb, Neumann E, Rakow R, Altman M, et al. Conservative management of gangrene in the diabetic patient. Bull Soc Int Chir. 1962;21:473-80.

20. Susumu Miyajima et al; Risk factors for major limb amputations in diabetic foot gangrene patients Diabetes Res Clin Pract 71:272-9. 2006. 